\title{
INCLUSÃO EDUCACIONAL DE ALUNOS COM SÍNDROME DE DOWN
}

\author{
Alvaro Rego Millen Neto \\ Mestre em Educação Física pela Universidade Gama Filho e professor do Centro Universitário de Barra Mansa.
}

T.J. Cardoso Silva

Licenciado em Educação Física pelo Centro Universitário de Barra Mansa.

\begin{abstract}
Resumo
Trata-se de uma pesquisa etnográfica que investiga a tentativa de inclusão de três alunos com Síndrome de Down em uma escola pública. A coleta de dados foi realizada por meio de fichas de observação etnográfica e um diário de campo. A análise das informações coletadas permite as seguintes considerações: a) dentro de uma proposta de inclusão educacional se esconde uma forma incisiva de segregação - dois dos alunos investigados têm espaço/acesso restrito na escola; b) por outro lado, e paradoxalmente, a pesquisa também demonstra possibilidades de inclusão - o terceiro aluno freqüenta uma turma regular de $4^{\mathrm{a}}$ série do Ensino Fundamental de forma plena; c) fatores externos à escola, como a presença e o apoio da família, influenciaram sobremaneira o processo de inclusão educacional no locus investigado.
\end{abstract}

Palavras-chave: inclusão educacional - Síndrome de Down - Educação Física

\section{Introdução}

artigo trata da temática das possibilidades concretas da inclusão educacional de pessoas com Síndrome de Down na escola pública brasileira. Pretendemos confrontar os discursos que estão em voga sobre a inclusão com o cotidiano desses alunos que freqüentam um Centro Integrado de Educação Pública (CIEP) municipalizado localizado numa cidade da região sul-fluminense. ${ }^{1}$

Delimitando o foco da pesquisa, voltamos os esforços investigativos notadamente para questões associadas ao papel dos professores que atuam com a Educação Física e atendem a alunos com Síndrome de Down na referida instituição. Tal opção se justifica a partir da compreensão de que é por meio da educação

1 A cidade e os demais dados que poderiam vir a identificar os alunos investigados foram omitidos. que começamos a quebrar os paradigmas e os preconceitos impostos pela sociedade, sendo de importância capital a qualificação da comunidade escolar para que saiba lidar com a temática da inclusão. Nesse sentido, consideramos que são vários os aspectos que envolvem a questão da inclusão educacional, sendo a qualificação dos professores um dos primordiais. É essencial que o professor saiba lidar com a turma em relação à aceitação, a fim de obter a compreensão de todos a respeito dos direitos das pessoas com deficiências em relação ao acesso a bens públicos e a uma educação de qualidade.

São requisitos para essa educação inclusiva de qualidade: rever os métodos de ensinoaprendizagem e de avaliação, ter a participação plena de todos como princípio fundamental, propiciar ambientes educacionais agradáveis e, principalmente, fazer com que as pessoas possam ver e tratar o tema da inclusão educa- 
cional com o devido cuidado, evitando a reprodução de práticas e ideais discriminatórios e preconceituosos.

A problemática da discriminação social tem incidido sobremaneira nos alunos com deficiências no âmbito escolar. Nesse sentido, pudemos verificar, em observações assistemáticas no locus investigado, que parte considerável dos responsáveis pelos alunos ditos normais, por desconhecerem as características e os direitos sociais dos alunos especiais, acabam por reivindicar medidas segregadoras, tais como a exclusão dos alunos especiais do contexto regular de ensino.

A partir dessa situação problema, o estudo pretende elucidar as seguintes questões: Como ocorre o atendimento educacional para alunos com Síndrome de Down no CIEP investigado? De fato, há uma inclusão educacional? Quais são os espaços pedagógicos para as aulas regulares dos alunos com Síndrome de Down? Quais são os espaços para suas aulas de Educação Física? Quais são as dificuldades enfrentadas para a concretização da inclusão desses alunos (por parte dos professores, da escola e dos próprios alunos)? Como os alunos com Síndrome de Down são recebidos pelos demais alunos nas aulas regulares e nas aulas de Educação Física? Como eles são vistos pelos demais alunos, pelos professores e pela direção da escola?

Trata-se de uma pesquisa qualitativa, com características etnográficas, na qual os pesquisadores se envolveram com o cotidiano investigativo no sentido de colher informações in loco, ou seja, vivenciaram os aspectos culturais intrínsecos ao ambiente da escola. Os instrumentos para a coleta de dados foram as fichas de observação etnográfica e um diário de campo. Assim, foram relatadas as informações sistematicamente coletadas pelas fichas de observação e realizada uma descrição geral das informações mais relevantes, de cada visita à escola, no diário de campo.

\section{Integração e inclusão}

Os termos integração e inclusão, que atualmente estão amplamente disseminados nas mais diversas esferas da sociedade, começam a ser forjados na segunda metade do século $\mathrm{XX}$ e têm relação com a organização de políticas públicas que buscam a eqüidade. Entre elas, encontram-se as políticas educacionais, mostrando-se um caminho novo nas propostas de ensino e aprendizagem para populações especiais. Entretanto, para chegar à sua compreensão contemporânea, tais propostas eqüitativas passaram por diferentes etapas demarcativas (JANNUZZI, 2006).

Podemos localizar a gênese das idéias de eqüidade na década de 1950 , com o surgimento do princípio da normalização. Em crítica às modalidades de atendimento de tendência segregadora e centralizadora, tal princípio preconizava às pessoas com necessidades especiais estilos de vida, e acesso a bens públicos, tão próximos quanto possível dos padrões ditos normais da sociedade (SEABRA JUNIOR, 2006).

Um bom exemplo do ideal de normalização pode ser visto na Campanha Nacional pelo Livro Didático. Podemos considerar que tal campanha foi uma das primeiras formas de políticas públicas brasileiras que incluiu em sua matriz norteadora, ainda na década de 1950, a possibilidade de atender pessoas com necessidades especiais em instituições regulares de ensino - um de seus vieses pretendia massificar livros didáticos em Braile, a fim de que as pessoas cegas pudessem acompanhar as aulas das escolas regulares.

De acordo com Jannuzzi (2006), notadamente ligado à deficiência mental, em fins de 1970 e início da década de 1980 penetrou no Brasil o princípio de mainstreaming, de integração. Nascido na Dinamarca - em 1959 já estava incorporado à legislação desse país -, pretendia uma "integração progressiva na corrente da vida com os considerados normais, de modo que o deficiente fosse aceito na 
escola e na sociedade" (JANNUZZI, 2006, p. 181). Para tal, esse princípio considerava fundamental que os alunos com necessidades especiais fossem inseridos nas escolas regulares. $\mathrm{E}$, as classes especiais foram eleitas como o local adequado para esses atendimentos educacionais.

Entretanto, na concepção de Sassaki (1997, apud SEABRA JUNIOR, 2006, p. 48), o movimento da integração visava a inserção social das pessoas com necessidades especiais que atingissem determinado grau de competência. A condição de adaptar-se ao meio caberia a esses indivíduos. Desse modo, "a sociedade aguardava a chegada dessa população sem se preparar para tanto, acreditando que sua parcela de responsabilidade estaria cumprida" (SEABRA JUNIOR, 2006, p. 48).

O início da década de 1990, notadamente a partir da Declaração de Salamanca (BRASIL, 1994), significou uma quebra paradigmática nas propostas de eqüidade educacional. O princípio da inclusão surge como uma superação ao modelo de integração, pois, de acordo com a referida declaração,

[...] em vez de focalizar a deficiência da pessoa, enfatiza o ensino e a escola, bem como as formas e condições de aprendizagem; em vez de procurar, no aluno, a origem de um problema, define-se pelo tipo de resposta educativa e de recursos e apoios que a escola deve proporcionar-lhe para que obtenha sucesso escolar; por fim, em vez de pressupor que o aluno deva ajustar-se a padrões de "normalidade" para aprender, aponta para a escola o desafio de ajustar-se para atender à diversidade de seus alunos (BRASIL, 1994, p. 12).

Nesse sentido, a concepção de inclusão pressupõe que a tarefa de adaptação, de transformação, não cabe mais aos alunos especiais, e sim à escola e à sociedade. Portanto, a idéia de buscar a normalização, desconsiderandose e/ou eliminando-se as diferenças dá lugar ao altruísmo. Não cabe mais entender a escola como o lugar das padronizações, no qual prevalecem as características ditas normais.
Por fim, e considerando a ressalva de Carvalho (2006), é importante advertir sobre um possível mal entendido. Quando se critica a proposta de integração, não se está a criticar a conotação que esse termo tem na língua portuguesa, mas sim a concepção de normalização que está impressa nele. Outrossim, não entendemos a idéia de integração em oposição maniqueísta à de inclusão. De acordo com Kuhn (2000), os novos paradigmas não descartam o auxílio dos antigos, uma mudança de paradigma que desconsidere $o$ conhecimento e as técnicas existentes pode inibir o desenvolvimento da ciência. Assim, o processo de inclusão deve considerar todas as condições que o viabilizem. Entre elas, as estratégias creditadas ao modelo integracionista, como o apoio suplementar ao ensino.

\section{A escola investigada}

O CIEP investigado possui 25 salas de aula, uma sala de informática, um auditório, um refeitório grande, cozinha, seis banheiros, uma quadra poliesportiva coberta e uma biblioteca aberta à comunidade. Os horários de aula estão divididos em três turnos: matutino, das sete às 12 horas, atendendo ao ensino de $5^{\mathrm{a}}$ a $8^{\mathrm{a}}$ série do Ensino Fundamental, com 406 alunos; vespertino, das 13 às 17 horas e 30 minutos, quando são desenvolvidas as aulas da Educação Infantil à $4^{\mathrm{a}}$ série do Ensino Fundamental, com 380 alunos; e noturno, das 18 às 22 horas, quando ocorre a Educação de Jovens e Adultos (EJA), com 394 alunos. Os 160 funcionários lotados na escola estão divididos nas áreas de serviços gerais, cozinha e inspetoria de disciplinas, além dos 76 professores.

Por ser municipalizada, a escola ainda recebe alguns projetos da prefeitura que utilizam as suas instalações, mas não fazem parte de sua proposta pedagógica. São desenvolvidos em suas dependências três projetos sociais, com atividades esportivas, de dança e circenses, e atendimentos psicológico e de as- 
sistência social. Desse modo, por estar situado em um município de pequeno porte, o CIEP funciona como um pólo aglutinador das políticas públicas locais, e tem funções sociais que extrapolam as tradicionalmente reservadas à educação formal.

O que poderia se tornar um elemento enriquecedor acabou por se tornar, em função de sua desconexão com o currículo vivido pela escola, um estorvo para professores e funcionários. É nítida a insatisfação de tais profissionais com a presença desses programas sociais no interior da escola. Obviamente, isso não significa que são contra a efetivação dos projetos sociais, considerados fundamentais para o exercício da cidadania da população local. O problema concentra-se na utilização do espaço da escola para políticas públicas que deveriam ter seus próprios espaços, pois atrapalham o desenvolvimento das atividades regulares da escola, quando contribuem para obliterar o controle das pessoas (notadamente as crianças) que circulam pelas dependências da escola.

O CIEP localiza-se em um bairro periférico e atende a quatro comunidades carentes vizinhas. Tal característica reflete-se nos quadros de atendimento extra-educacional, tais como a importância da merenda para presença das crianças na escola, suplantando muitas vezes o próprio interesse pelas questões pedagógicas. Nesse sentido, observamos sistematicamente, principalmente no turno da manhã, crianças que não demonstram interesse pelos estudos, fogem das salas de aula e ficam andando pela escola, misturadas àquelas atendidas pelos programas sociais.

Enfim, trata-se de uma escola que se esforça para manter uma educação de qualidade, mas que encontra dificuldades, como grande parte das escolas da rede pública nacional. São com essas características, e suas adversidades, que o CIEP investigado se propõe a incluir em seus bancos (e quadras) três adolescentes com Síndrome de Down. Eles não são os primeiros; obtivemos relatos de outros quatro alunos egressos com essa particularidade.

\section{Os alunos com Síndrome de Down}

Dos três alunos com Síndrome de Down matriculados no CIEP, dois estão inseridos em classe especial e o terceiro está freqüentando uma classe regular. Reportamo-nos aos alunos chamando-os de aluno 1 , aluno 2 e aluno 3, a fim de preservar suas identidades para observarmos seus comportamentos e suas características sem comprometer suas integridades.

\section{ALUNO 1}

O Aluno 1 é do sexo masculino, tem 16 anos de idade, baixa estatura e encontra-se acima do peso. Trata-se de um rapaz muito afetivo e que possui uma sexualidade aflorada, cuja feminilidade é marcante em seus traços comportamentais. No transcorrer da investigação, ficou sugerido que tais normas de comportamento foram reforçadas pelo tipo de convivência familiar na qual esse garoto está submetido, pois ele foi criado no meio das irmãs sem a presença de uma figura masculina, uma vez que o pai viaja muito e nem sempre está presente. Com isso, o Aluno 1 cresceu observando as irmãs se arrumando, se maquiando, colocando roupas femininas e assim, supostamente, acabou por naturalizar tais comportamentos como sendo universais.

Nas aulas de alfabetização e também nas de artesanato, o aluno demonstra grande dificuldade no aprendizado, não consegue escrever seu nome, possui uma coordenação motora fina bem prejudicada e fica constantemente disperso. As professoras sempre estão chamando a sua atenção em função de seu comportamento, mas ele possui um comportamento instável.

Com relação à sua motricidade, o Aluno 1 possui uma coordenação motora grossa boa. Certa vez o professor pediu-lhe para que executasse o movimento de zig-zag com a bola de basquete, entre os cones, e ele se saiu muito bem. Também notamos que consegue realizar 
exercícios que alunos ditos normais não conseguem executar com facilidade.

\section{ALUNO 2}

O Aluno 2 é do sexo masculino, tem 17 anos, baixa estatura e está acima do peso ideal. Possui um comportamento por demais agressivo, não é muito afetivo, gosta de ficar sozinho e também possui a sexualidade bastante aflorada.

A partir do relato de seu professor de Educação Física, sobre questões acerca de sua sexualidade, verificamos que o seu comportamento melhorou, pois há algum tempo ele não podia ver uma mulher bonita e bem apresentável que logo abaixava as calças, onde quer que estivesse, e começava a se masturbar. Obtivemos relatos de que ele vivia se masturbando em sala de aula. Os professores realizaram um árduo trabalho para explicar-lhe que a masturbação em público não é socialmente aceita e que havia lugares e horas certos para realizá-la.

Em relação à sua agressividade, pudemos perceber, nas aulas dentro de sala, constantes práticas de agressividade, tais como os socos dados em seus amigos, chutes e gestos agressivos. Obtivemos relatos de uma passagem na qual, na hora do recreio, quando uma criança estava a beber água, o Aluno 2 deu um tapa na cabeça do menino, levando-o a bater com a boca no bebedouro e a se ferir. Nesse dia ele foi levado para a direção e recebeu uma suspensão. Passaram-se dias e seus pais não apareceram na escola para tomar ciência do ocorrido. Procuramos mais informações a esse respeito e descobrimos que o Aluno 2 passa os dias sozinho, sem a presença de familiares e constantemente chega a se envolver em brigas e confusões na rua, o que demonstra que sua família não é presente.

Em relação à capacidade de aprendizagem, ele se diferencia um pouco do Aluno 1, pois consegue escrever seu nome, mesmo que de forma grosseira. Sua coordenação motora fina é interessante, o observamos copiar com êxito um desenho do livro de histórias, reproduzindo os contornos e as cores corretamente.

Nas aulas de Educação Física ele é sempre participativo e consegue se destacar nos exercícios de habilidade, tais como quicar a bola de basquete entre os cones e na corrida. Mas ficou perceptível que ele falta a muitas aulas. Outro ponto que se fez notar, ao observarmos o Aluno 2, foi uma grande vontade de estar incluso na classe regular, como as demais crianças da escola.

\section{ALUNO 3}

O aluno 3 também é do sexo masculino, tem 17 anos, baixa estatura e é bem mais magro do que os alunos 1 e 2 . Esse aluno é incluso na classe regular, cursa a $4^{a}$ série do Ensino Fundamental e ficou claro que teve uma educação familiar diferenciada. Seus pais sempre estiveram presentes em sua vida, se preocupam com seu desenvolvimento e educação e com os valores éticos e sociais.

Trata-se de um rapaz conhecido por todos na cidade e muito querido. É um adolescente amável e muito carismático, sempre participativo nas aulas, tanto dentro de sala de aula como nas aulas de Educação Física. Desde o primeiro contato, se mostrou educado e amigo. Brinca normalmente com as outras crianças da escola e com seus colegas de turma. Em contrapartida, a comunidade escolar demonstra muito afeto por ele.

A diferença fica nítida ao compará-lo com os alunos 1 e 2 . Nesse sentido, a presença de sua família, sempre preocupada com seu desenvolvimento, mostrou-se uma marca desse diferencial. Desde cedo, os pais procuraram ajudá-lo para que se desenvolvesse, propiciando atendimento em várias entidades especializadas no aprendizado de crianças portadoras de necessidades especiais.

Nas aulas de matemática e português, a sua capacidade de memorização é muito boa, ele faz os mesmos exercícios e deveres que as 
professoras passam para seus colegas de turma, e também é avaliado de igual forma. As professoras comentam seu comportamento e elogiam. Sua professora de Educação Física se derrete em elogios, pois ele se destaca nas aulas participando de todas as atividades.

\section{As classes especiais}

A classe especial do CIEP investigado surgiu há três anos com a proposta de alfabetizar e fazer a inclusão dos portadores de necessidades especiais da cidade. Nesse período, já passaram vários alunos por essa classe e também vários professores. Atualmente, a classe especial tem 13 alunos, todos deficientes mentais, mas com a intensidade variando entre severa, moderada e leve. Atualmente conta com três professores: duas professoras que têm formação de magistério e trabalham com a parte pedagógica e de artesanato, e um professor de Educação Física.

No decorrer das observações sistemáticas, conversamos com as professoras sobre o fato de os alunos 1 e 2 não estarem incluídos na classe regular. De pronto, elas responderam que seria muito difícil, pois alguns professores da classe regular se sentem despreparados para lidar com eles, e que também os alunos 1 e 2 têm um déficit bastante grande e talvez não conseguissem se adaptar.

Observamos certa insatisfação por parte das professoras em função da falta de apoio para desenvolver o trabalho com a classe especial, tais como uma sala adequada, materiais pedagógicos e outros instrumentos para que se possa fazer um trabalho especializado.

A classe realiza as seguintes atividades: na segunda, das 8 às 11 horas e 30 minutos, desenvolve o trabalho com horta, os alunos aprendem a plantar e a mexer com a terra; na terça, das 13 às 17 horas e 30 minutos, atividades pedagógicas e atividades manuais (artesanato); na quarta, das 13 às 15 horas e 30 minutos, as aulas são desenvolvidas na sala de leitura com o professor, que conta histórias e propicia o contato com livros; na quinta, das 13 às 17 horas e 30 minutos, aulas em sala até a hora do recreio e depois aulas de Educação Física; na sexta, das 13 às 17 horas e 30 minutos, o mesmo procedimento que ocorre na quinta. $\mathrm{O}$ recreio ocorre junto com o dos demais alunos da escola, das 15 às 15 horas e 30 minutos.

No horário do recreio, eles descem e merendam com as outras crianças normalmente, entretanto, após o término da merenda, as professoras são praticamente obrigadas a ficarem com eles como se fossem guarda-costas. Elas não podem deixá-los soltos com o resto das crianças, sob o argumento de que pode acontecer alguma coisa - como foi o caso do aluno 2, que machucou uma criança no bebedouro. Ou seja, as professoras se sentem presas, pois os inspetores de disciplinas questionam que não podem ficar olhando apenas os alunos especiais, pois têm outras crianças para tomar conta e não são babás - deixando explícita a forma com que vêem as pessoas com deficiências. É uma situação complicada, pois, em seus relatos, essas professoras se dizem estar de pés e mãos atados.

Mediante as observações etnográficas e as conversas com os professores, ficou explícito que a classe especial serve como uma válvula de escape. Não há, portanto, uma proposta de inclusão educacional mais ampla, no sentido de possibilitar aos alunos o acesso a uma educação completa e da interação com os demais membros da comunidade escolar. Poderíamos, amparados por Sassaki (2002), considerar uma proposta de segregação por detrás da pretensa inclusão, quando na verdade a classe especial serve de locus no qual as crianças especiais são postas a fim de evitar o convívio (contaminação) com os demais alunos. Na realidade, é uma forma de segregação ainda mais intensa do que em uma escola especializada.

Outrossim, ficaram pistas de que a grande maioria dos pais dos alunos especiais se ausentam das questões sobre o aprendizado de seus filhos. Infelizmente, provavelmente em função das dificuldades do dia a dia, aumen- 
tadas pelo nascimento de uma criança carente de cuidados especiais, nem todos os pais estão preocupados com o crescimento e o desenvolvimento de seus filhos, o que importa para estes é a presença de seus filhos na escola, independentemente do modo com que ela se dá.

\section{A educação física para os alunos com Síndrome de Down}

As aulas de Educação Física foram um momento especial na pesquisa, pois, além de ser um dos objetos de investigação, era um espaço em que os comportamentos, gestos e habilidades de cada aluno mais vinham à baila. Primeiramente abordaremos as aulas de Educação Física do Aluno 3, uma vez que esse rapaz fazia tais aulas em separado dos demais, pois freqüenta a classe regular de ensino da $4^{a}$ série do Ensino Fundamental. Ele faz, portanto, as aulas junto com os alunos da sua turma.

O Aluno 3 possui uma habilidade motora bastante desenvolvida, a ponto de, em diversas ocasiões, se destacar dos demais alunos, demonstrando-se ativo e participativo nessas aulas. A professora se surpreende com sua desenvoltura. Observamos as aulas de voleibol e ficou perceptível que sua habilidade de dar toques e manchetes é igual à dos demais alunos da turma.

Freqüentemente, o Aluno 3 pega a bola e solicita uma partida de futebol, o seu esporte preferido. Ele também pratica futebol fora da escola, jogando e treinando em um clube da cidade nas terças e quintas-feiras e nos fins de semana. Todos no time o respeitam e o tratam normalmente, sem diferença nenhuma. Inclusive, quando perde uma jogada, recebe repreensões. Ele possui uma vida esportiva normal.

Quanto às aulas de Educação Física para a classe especial, da qual os alunos 1 e 2 fazem parte, as atividades trabalhadas sãos as seguintes: diferentes tipos de jogos (pequenos e grandes), jogos adaptados, atividades instrutivas com líderes, ambas com o objetivo de trabalhar exercícios de coordenação, equi- líbrio, lateralidade, noções de espaço e socialização.

Durante o período que antecede as competições especiais das quais participam, o professor realiza atividades que visam a preparação dos alunos para esses eventos. Para tal, são utilizadas algumas aulas em horário regular e também aulas extras. Os Alunos 1 e 2 conseguem se desenvolver bem nas atividades que consistem em correr, saltar, arremessar e fazer zig zag. Eles demonstraram-se bem serenos durante a competição, se divertiram, dançando no dia da abertura e ficaram tranqüilos nos dias das provas.

Certo dia, o professor promoveu uma integração dos alunos da classe especial com as crianças do programa social - de educação circense - desenvolvido nas instalações da escola. Eles iriam participar de um evento esportivo, fazendo a abertura, e o Maculelê da Capoeira foi a atividade elencada. Cada aluno do circo fez par com um aluno da classe especial e ficaram responsáveis por mostrar e ensinar o ritmo e as batidas. Esse trabalho durou três semanas e, a cada aula, nos surpreendemos com a evolução deles nos movimentos do Maculelê. Nesse período de aprendizagem, os alunos do circo trataram os alunos da classe especial sem nenhum tipo de preconceito ou discriminação.

$\mathrm{O}$ aluno 2 ainda pratica basquete em um projeto de uma ONG perto de sua casa, por isso, nas aulas de Educação Física, demonstra um considerável domínio de bola. Esse fato serviu para reforçar o entendimento de que a escola sozinha não poderá resolver todas as questões de aprendizagem; o auxílio e a presença de pessoas e projetos externos formaram um leque de experiência que favoreceram contundentemente o desenvolvimento desses alunos.

\section{Considerações finais}

A investigação etnográfica realizada no CIEP, que sediou a pesquisa com os alunos com Síndrome de Down, possibilitou-nos uma aproximação interessante com as carac- 
terísticas do processo de inclusão educacional de pessoas com deficiências. Pudemos observar como, de fato, se dão as políticas de inclusão em uma escola pública, para muito além dos discursos politicamente corretos que pregam chavões sem pisar no "chão da escola".

Nesse sentido, explicitamos alguns pontos relevantes para elucidar as nuances desse complexo processo. Em primeiro plano, destacamos a necessidade de entender a inclusão como uma filosofia social que prega a igualdade de direitos e o respeito às diferenças que, para sair do plano abstrato e tomar corpo em projetos concretos, não pode ficar a cargo de uma única instituição, como a escola. Isso se desvelou quando percebemos que, de três alunos com Síndrome de Down matriculados na escola investigada, apenas um poderia se considerar educacionalmente incluso. Obviamente que muitos dos fatores contribuintes para essa inclusão eram externos à escola. As possibilidades de presença e apoio da família do Aluno 3 foram preponderantes nesse processo.

Apesar de não poder ser considerada isoladamente, a escola tem que tomar partido no processo de inclusão educacional. De acordo com Imbernón (2000), a igualdade de oportunidades e a eqüidade são os desafios mais importantes para o processo de inclusão. Assim, enquanto política pública, a escolarização tem que oferecer as mesmas oportunidades de formação para todos. E, para tal, deve adaptar-se às características específicas de seus alunos, notadamente às daqueles com deficiências, no sentido de respeitar as diferenças e, assim, tornar-se mais justa (eqüitativa).

Também verificamos que, dentro de uma proposta de inclusão educacional, escondiase uma segregação ainda mais incisiva que as operadas pelas criticadas escolas especializadas. Aos dois alunos inseridos na classe especial, era obliterada a possibilidade de interagir com os demais personagens da comunidade escolar, sob a argumentação discriminatória de que seriam nocivos a esses alunos. Assim, sob o discurso de uma inclusão que, como vimos, não ocorria, esses alunos com Síndrome de Down freqüentavam uma escola regular, mas sob a tutela de um espaço/tempo restrito ao convívio com os seus colegas com deficiências.

Por outro lado, e paradoxalmente, a pesquisa também sugeriu possibilidades de inclusão. Na mesma escola, tivemos um aluno com Síndrome de Down freqüentando uma turma regular da 4a série do Ensino Fundamental. No entanto, apesar de estar participando plenamente das atividades desenvolvidas em sua turma e de interagir otimamente com seus colegas, seria precipitado dizer que houve uma inclusão educacional com esse aluno. Seria mais sensato pensarmos numa integração, uma vez que não foi a escola que se preparou para receber esse aluno, ele próprio é que foi preparado para freqüentar a escola.

Nas aulas de Educação Física e nas atividades esportivas extracurriculares, o quadro em muito se assemelha ao do restante do processo educacional pretensamente inclusivo. Ou seja, novamente os dois alunos que estavam inseridos na classe especial ficaram restritos ao espaço destinado aos alunos especiais. Suas aulas de Educação Física eram realizadas em horários específicos e freqüentadas unicamente por alunos com deficiência mental. E, quando esses alunos participavam de atividades esportivas fora da escola, elas se realizavam em competições voltadas a alunos especiais. Faz-se exceção às aulas de basquete que um dos alunos da classe especial freqüentou. Já o aluno integrado à turma regular fazia as aulas de Educação Física com os alunos de sua turma de $4^{\mathrm{a}}$ série, e também se mostrou (bem) integrado no esporte fora de escola, no clube em que joga futebol.

Por fim, o envolvimento com os alunos com Síndrome de Down e com as tentativas de inclusão (ou integração) nos mostrou que, se por um lado a criança com Síndrome de Down tem muito a ganhar, em termos sócioafetivos, permanecendo no ensino regular, a descrição da escola investigada demonstrou 
poucas alternativas para incluir esses alunos. A questão que deixamos para futuras investigações é a de como evitar a exclusão e ao mesmo tempo incentivar a criança em seu desenvolvimento intelectual e emocional. De uma coisa sabemos: os professores precisam estar conscientes de sua importância e da função que desempenham, caso tenham um aluno com Síndrome de Down em sala, pois é na relação concreta entre o educando e o professor que são fornecidos os elementos que possibilitam decisões educacionais mais acertadas.

\section{Educational inclusion of Down Syndrome students}

\section{Abstract \\ This is an ethnographic research which investigates the attempted inclusion of three Down Syndrome students in a public schools. Data was gathered through ethno- graphic observation forms and a field log. Data analysis allowed us to make the following assumptions: a) wi- thin the proposal of educational inclusion lies a sharp form of segregation, as two of the research subjects have limited access to the school; b) on the other hand - and this is a paradox -, research has also shown possibilities of inclusion, as the third research subject attends and has thorough participation in a regular $4^{\text {th }}$ grade class; c) out-of-school factors, such as family participation and support, had a great influence on the educational inclu- sion process in the investigated locus. \\ Keywords: educational inclusion - Down Syndrome - Physical Education \\ Inclusión educacional de alumnos con Síndrome de Down}

\section{Resumen}

Se trata de una investigación etnográfica que investiga la tentativa de inclusión de tres alumnos con Síndrome de Down en una escuela pública. La recolecta de datos fue realizada por medio de fichas de observación etnográfica y un diario de campo. El análisis de las informaciones recolectadas permite las siguientes consideraciones: a) dentro de una propuesta de inclusión educacional se esconde una forma incisiva de segregación - dos de los alumnos investigados tienen espacio/acceso restricto en la escuela; b) por otro lado, y paradójicamente, la investigación también demuestra posibilidades de inclusión - el tercer alumno frecuenta un grupo regular de $4^{a}$ grado primario; c) factores externos a la escuela, como la presencia y apoyo de la familia, influenciaron sobremanera el proceso de inclusión educacional en el locus investigado.

Palabras-clave: inclusión educacional - Síndrome de Down - Educación Física

\section{Referências}

BRASIL. Ministério da Justiça. Secretaria dos Direitos Humanos. Declaração de Salamanca e linha de ação. 2. ed. Brasília: CORDE, 1994.

CARVALHO, Rosita Edler. Educação Inclusiva: com os pingos nos "is". 4. ed. Porto Alegre: Mediação, 2006.

IMBERNÓN, F. (Org.). A educação no século XXI: os desafios do futuro imediato. Trad. Ernani Rosa. 2. ed. Porto Alegre: Artmed, 2000.

JANNUZZI, Gilberta de Martino. A educação do deficiente no Brasil: dos primórdios ao início do século XXI. 2. ed. Campinas, SP: Autores Associados, 2006.

KUHN, Thomas S. A estrutura das revoluçôes científicas. 5. ed. São Paulo: Perspectiva, 2000.

SASSAKI, Romeu Kazumi. Inclusão: construindo uma sociedade para todos. 4. ed. Rio de Janeiro: WVA, 2002.

SEABRA JUNIOR, Luiz. Inclusão, necessidades especiais e educaçẫo física: considerações sobre a ação pedagógica no ambiente escolar. 2006. 119 f. Dissertação (Mestrado em Educação Física) - Faculdade de Educação Física, Universidade Estadual de Campinas, Campinas, 2006.

Recebido: 31 de março de 2008

Aprovado: 16 de julho de 2008

Endereço para correspondência

amillen@gmail.com

tjcandres@gmail.com 